\title{
Preface: Research Approaches to the Study of Religion
}

\author{
Lluis Oviedo \\ Antonianum University, \\ Rome, Italy \\ e-mail: loviedo@antonianum.eu
}

\begin{abstract}
Preface to the special issue 'Research Approaches to the Study of Religion'. First of all we pay attention to cognitive studies of religion and compare theology and philosophy of religion.

Keywords: cognitive science, cognitive science of religion, theology, religion.
\end{abstract}

The study of religion has known a great expansion in the last twenty years, despite its apparent decline in most Western areas. This is a curious and enigmatic trend. When I attended the Annual Meeting of the Society for the Scientific Study of Religion for the first time in 2001, I had to choose among 10 different panels of papers taking place simultaneously. The last time I attended the same Meeting two years ago, I had to choose among 16 panels; we had moved from an average of 300 to almost 500 presentations. The number of specialized journals and book series devoted to the new scientific study of religion has multiplied, and the available bibliographies and data bases keep growing steadily. It is hard to render a systematic review on issues like 'religion and prosocial behaviour' (more than 140 published papers) or even new scientific theories trying to explain religious origins and evolution (more than 70 papers from different authors).

Scholarly institutions devoted to the study of religion are thriving, like the traditional American Academy of Religion with its massive annual conferences, and the new attempt to institute a European version, the European Academy of Religion, to be launched on the $5^{\text {th }}$ of December 2016 in Bologna. This tendency is reflected in institutional changes, like the moves to convert old Theology Faculties or Divinity Schools into 'Theology and Religion' ones, broader in scope and covering fields like 'Religious studies' and the new brand usually called 'Cognitive Science of Religion', which often includes biological and neurological approaches as well.

All these moves claim for some interpretation. Indeed, something important is happening in the field of the academic study of religion that affects the traditional approaches represented by theology and - more recently - by philosophy of religion. Religion attracts the interest of many scholars and becomes unexpectedly the object of intensive and well-founded research. We are clearly moving from what could be called an 'internal hermeneutics' towards an external one, from a focus on the texts and history, which has nourished a long season in theology and exegetics, towards a focus on empirical and even experimental approaches, applying quite different theoretical frameworks, like cognitive sciences, behavioural and evolutionary psychology, and even comparative psychology or primatology.

The new interest that religion awakes can be explained by very broad and very concrete or closer reasons. The latter is a result of some 'religious resurgence', as has been claimed in many 
world areas with virulent irruptions in the last twenty years, when religious factors have been determinant in many political and social settings. We could not ignore that variable when several phenomena needed an in depth explanation. The other reasons go beyond the conjunctural, and rather point to the very enigmatic nature of religion and how its very essence challenges most attempts at understanding it or at coming to terms with its truth claims. In short, religion has to do with what is of ultimate value and meaning, and hence thinking about religion is like trying to grasp our own last reasons and our own last fundaments. Reversing the Anselmian Argument, the attempt to think the meaning of the Divine reflects our need to account for the most important and relevant aspects in our life and our reality. In that sense, stopping studying religion would be like bringing to a close our intellectual endeavour to understand reality to its end, in its whole.

The last sentences could sound as celebratory regarding all that is going on in the field of the new scientific study of religion. Unfortunately, this is not the case in most published researches. Contrasting with the great ambition and scope in the study of religion, much of the current production lacks that depth and large horizons. The current research is much narrower and focuses on immediate causes and dynamics presiding over religious beliefs and behaviours. Its aim is often to reveal the hidden mechanisms, the subtle dynamics behind the religious mind and behaviour, often their style resembles more a scientific version in deconstructive practice. That approach often becomes disappointing but might turn useful and necessary as well, provided that it does not prevent a view able to appreciate the broad picture. Part of the problem derives from the excess of reductionism in the scientific treatment of religion, the obsession with details and basic levels that inhibits a better perspective, one able to account for the great variety and richness represented in so many religious expressions.

Theology and Philosophy of Religion cannot ignore all that is happening in that research field. There is too much at stake and regrettably too few scholars in that academic fields devoting their time and interest to follow such developments and trying to learn from them or to apply their findings to theological hermeneutics. This is a task that could be discouraged by the same paucity resulting from a closer and critical examination about the ongoing research. Indeed, too many outcomes from the standard cognitive science of religion have been harshly debunked because of their poor theoretical ground and the scarcity of empirical evidence their authors provide. The temptation could be to ignore and neglect all this research corpus as completely irrelevant for theologians and philosophers, used to alternative methods and hermeneutical or normative approaches. In my opinion it would be a mistake. Even if we are more and more aware of the mounting flaws afflicting that scientific approach, we should nevertheless learn from their many achievements and the ongoing discussions, something I find highly instructive, together with most recent developments and attempts to move beyond the standards reached so far and to explore fields that were left beside in the first waves of that program, like culture, meaning and symbols.

Our expectation is that a new generation in the scientific study of religion assumes a less reductive stance and becomes able to take into account central aspects of those very human and social experiences to help to better understand its dynamics, to improve its application and to prevent its worse expressions. The articles contained in this special issue clearly reflect that spirit and open to a brighter panorama. 